Miledi, R. (1960). F. Physiol. (Lond.), 154, 190.

Miller, H. G., and Daley, R. (1946). Quart. F. Med., 15, 255. Stanton, J. B., and Gibbons, J. L. (1956). Ibid., 25, 427

Murray, I. P. C., and Simpson, J. A. (1958). Lancet, 1, 1360

Nattrass, F. J. (1921). F. Neurol. Psychopath., 2, 159.

Parsonage, M. J., and Turner, J. W. A. (1948). Lancet, 1, 973.

Peters, R. A., Sinclair, H. M., and Thompson, R. H. S. (1946). Biochem.

7., 40, 576.
Refsum, S. (1946). Heredopathia atactica polyneuritiformis. Tanum, Oslo.

Schmitt, F. O. (1958). Exp. Cell Res., Suppl., 5, 33.

Simpson, J. A. (1956). F. Neurol. Neurosurg. Psychiat., 19, 275. (1962a). In Modern Trends in Neurology, edited by D. Williams, Chapt. 14, 3rd series. Butterworths, London.

(1962b). Dev. Med. Child Neurol., 4, 55.
- (1962c). In Progress in Electromyography, edited by P. Pinelli, p. 36. Elsevier, Amsterdam.

(1964). Biochem. Clin. In press.

Spillane, J. D. (1947). Nutritional Disorders of the Nervous System. Livingstone, Edinburgh.

Teilum, G. (1948). Amer. F. Path., 24, 389.

Thage, O., Trojaborg, W., and Buchthal, F. (1962). Dan. med. Bull., 9, 26."

Victor, M., Banker, B. Q., and Adams, R. D. (1958). 7. Neurol. Neurosurg. Psychiat., $21,73$.

Waksman, B. H., and Adams, R. D. (1955). 7. exp. Med., 102, 213.

W (1956). 7. Neuropath. exp. Neurol., 15, 293.

Waldenström, J. (1961). Harvey Lect., 56, 211.

Weiss, P., and Hiscoe, H. B. (1948). F. exp. Zool., 107, 315.

Wohlfart, G. (1958). Neurology (Minneap.), 8, 175.

\title{
Clinical and Radiological Results of Repair of Hiatus Hernia
}

\author{
D. A. W. EDWARDS,* M.A., M.D., M.R.C.P.; S. F. PHILLIPS, † M.D., M.R.A.C.P. ; \\ E. N. ROWLANDS, $\ddagger$ M.D., B.SC., F.R.C.P.
}

Brit. med. F., 1964, 2, 714-718

There is a wide divergence of views among both surgeons and physicians about the indications for and the results of surgical repair of hiatus hernia. Some surgeons claim a high percentage of cures, while others have been so disappointed with a repair operation that they have given it up in favour of partial gastrectomy and vagotomy (Wells and Johnston, 1955). There are, too, a number of conflicting views about the best technique for the repair, each view based upon a different conception of what is the precise mechanism responsible for preventing gastrooesophageal reflux. An additional complication is introduced by the concept that the corrosive quality of the refluxed material can be reduced by partial gastrectomy or by vagotomy, and its quantity reduced by drainage.

Some of the difficulties encountered in trying to compare the results in one series of patients with those in another can be resolved by defining more precisely the standard of reference. For example, the radiologist may feel that a particular method of repair of the hernia is a poor one because of the high incidence of radiologically demonstrable hernia or reflux after operation; and the incidence that he finds will depend very much on his particular examination technique. The surgeon, already discouraged by what his radiological colleague reports, may be further discouraged when his patient admits to persisting, if less severe, symptoms of reflux. In the surgeon's view the operation has been an anatomical and functional failure.

We therefore attempted to assess the results of surgical repair from three aspects: (1) what the patient thought of the overall result, and of the effect of the operation on each symptom; (2) what the radiological appearances were; and (3) how far the patient's opinion of the overall result correlated with the operative procedure.

All the patients were under the care of and referred for surgery by two physicians specializing in gastro-enterology (Drs. F. Avery Jones and T. D. Kellock), whose policy has been to persevere with medical treatment and the successive trial of a variety of therapeutic measures unless very strong indications for surgery have been present. The patients had been selected for surgery, therefore, according to clearly defined criteria. The

* Physician and Member of the Scientific Staff, M.R.C.'s Gastro-enterology Research Unit, Central Middlesex Hospital, and Department of Clinical Research, University College Hospital Medical School, London.

† Travelling Scholar of the Royal Australasian College of Physicians.

$\ddagger$ Physician and Director, M.R.C.'s Gastro-enterology Research Unit, Central Middlesex Hospital, London. small number of patients in this series is merely a reflection of the reluctance to advise surgery except for patients with intractable symptoms. Out of a total of 894 new hiatus hernias diagnosed in the hospital's radiology department between January 1952 and January 1963 only 5-6\% were operated upon. All the operations in this series were performed by one surgeon (Mr. J. W. P. Gummer), but the follow-up was carried out by three general physicians who had never seen the patients before.

The purpose of this paper is (1) to draw attention to those symptoms which are likely to be usefully reduced in severity by repair of a hiatus hernia, and to those which are not; and (2) to emphasize that a large proportion of the patients were pleased with both the immediate and the long-term results, despite the fact that the majority still had radiological evidence of hernia or reflux, or both, and many still had mild symptoms.

\section{Patients and Methods}

An attempt was made to interview and examine radiologically all patients operated upon by one surgeon (Mr. J. W. P. Gummer) between January 1952 and January 1963. Most of them came from the local community, but some had been referred from various parts of Britain and overseas and had been investigated radiologically elsewhere. Patients who had been operated on for strictures were not included in the present series.

There were 63 patients ( 17 males, 46 females) who had been operated on for 60 sliding and 3 para-oesophageal hernias (diagnosis made at operation). Five patients had been followed up in the department until death, nine had been lost to followup after a variable period, and 12 others were unable to attend for interview but answered a detailed questionary by post. The remaining 37 were interviewed and examined by us. Table I shows the age distribution at the time of operation of those interviewed and of the whole series. Table II shows the number of patients operated upon each year, and Table III the length

TABLE I.-Age at Operation of Patients Personally Examined and of

\begin{tabular}{|c|c|c|c|c|c|c|}
\hline Age: & $20-$ & $30-$ & $40-$ & $50-$ & $60-$ & 70 \\
\hline $\begin{array}{l}\text { Whole series ... } \\
\text { Personally examined } \ldots\end{array}$ & $\begin{array}{l}2 \\
2\end{array}$ & $\begin{array}{l}7 \\
3\end{array}$ & $\begin{array}{r}11 \\
8\end{array}$ & $\begin{array}{l}20 \\
12\end{array}$ & $\begin{array}{l}19 \\
10\end{array}$ & $\begin{array}{l}4 \\
2\end{array}$ \\
\hline
\end{tabular}


of follow-up both for the group seen by us and for the total series.

TABLE II.-Number of Patients Operated Upon Each Year

\begin{tabular}{l|r|r|r|r|r|r|r|r|r|r|r}
\hline Year . . . & 1952 & 53 & 54 & 55 & 56 & 57 & 58 & 59 & 60 & 61 & 62 \\
No. of patients & 2 & 5 & 8 & 7 & 5 & 3 & 4 & 2 & 6 & 11 & 10 \\
\hline
\end{tabular}

TABLE III.-Length of Foilow-up in Years of Patients Personally Examined and of Whole Series

\begin{tabular}{r|r|r|r|r|r|r|r|r|r|r|r}
\hline No. of years: & $<1$ & $1-$ & $2-$ & $3-$ & $4-$ & $5-$ & $6-$ & $7-$ & $8-$ & $9-$ & $10-11$ \\
\hline Whole series ..... & 12 & 17 & 4 & 4 & 7 & 2 & 5 & 4 & 4 & 3 & 1 \\
Personally examined.. & 8 & 10 & 3 & 1 & 1 & 1 & 3 & 4 & 3 & 2 & 1
\end{tabular}

\section{Patients Personally Interviewed}

Patients who were able to come to the department were interviewed by two of us, who agreed on an interpretation of the patients' answers to an extensive questionary about their present and pre-operative symptoms. Afterwards the hospital records were scrutinized to check the patients' memories of their preoperative symptoms. They were then examined radiologically with a Marconi 5 -inch $(12.5 \mathrm{~cm}$.) image intensifier by one of us (D.A. W.E.) and another observer, using the following technique.

The patient sat on the horizontal $x$-ray couch leaning on the left elbow, drank $250 \mathrm{ml}$. of three parts Micropaque diluted with one part of water, and washed it down with $60 \mathrm{ml}$. of water. She then lay supine, was tipped 10 degrees head down, and the thorax was examined for evidence of hiatus hernia and reflux. (By "reflux" we mean any flow of gastric contents from stomach to oesophagus-that is, the cardiac sphincter is breached-whereas by "regurgitation" we mean the flow of oesophageal contents into the pharynx by mouth-that is, the cricopharyngeal sphincter is breached.) After raising her straightened legs for 30 seconds and lowering them, she turned on to her left side for about 30 seconds, then on to her back, turning to the left and back three times, or less if a hernia or reflux was seen. She then turned three times on to her right side. Any flow of barium into the oesophagus was recorded and the amount and freedom of flow roughly quantitated. The arbitrary time of about 30 seconds was chosen to exclude slow leaks at the gastro-oesophageal junction. At each position she was requested to swallow once in order to relax the cardiac sphincter. No pressure was applied to the abdomen, nor was the patient examined over a bolster or in the "toe-touching" position. If no hernia was outlined by these manœuvres she was given more barium to drink while supine 10 degrees head down to outline a loculus which might have been nipped off from the body of the stomach by the hiatus (Edwards, 1961, 1962). Special care was taken to distinguish a phrenic ampulla from a loculus of stomach (Edwards, 1961). A rough attempt was made at grading the size of the hernia.

\section{Patients Not Personally Interviewed}

Most of the patients who were unable to attend for interview had been followed up in the department for several years. An assessment of their pre-operative and post-operative symptoms was made from the records and from a postal questionary. The radiological result of the operation was assessed from the $x$-ray reports in the records. If the presence of a hernia or reflux had been reported at any stage post-operatively we assumed that this state was permanent, but we did not accept a report of " no reflux nor hernia" unless it coincided in time with the latest available account of the patient's symptoms: otherwise the radiological result was classified as "unknown."

\section{Reasons for Operating}

There were no emergency operations during this period. Fifty-four of the patients had failed to respond to medical treatment. In six of these there was evidence of slight bleeding, but this was not regarded in itself as a sufficient indication for operating. Bleeding was a positive indication for operation in the remaining nine patients ; in four of these it was presumed to be related to the hiatus hernia because no other relevant lesion was found at operation; in the other five the bleeding may have been caused by another lesion known before or found to be present at operation.

Additional, sometimes unsuspected, disease was found at operation in 16 patients and could have contributed to the symptoms: gall-stones (5), duodenal ulcer (4), duodenal ulcer and ileal carcinoid (1), gastric ulcer (3), gastric ulcer and gall-stones (1), gastric ulcer and chronic pancreatitis (1), and chronic pancreatitis (1).

\section{Surgical Procedures}

The thoracic approach was used in 32 operations, the abdominal in 29 , and a combined approach in two. The hiatus was sutured behind the oesophagus and the peritoneum around the hiatus repaired. In 36 patients a simple repair only was carried out ; in four patients a partial gastrectomy for gastric ulcer was done in addition to the repair. In the remaining 23 patients, in addition to the repair, vagotomy with drainage was carried out to reduce gastric secretion, and five of these had other lesions outside the stomach for which an additional operation was performed.

\section{Results}

We have divided our assessment of the results into four parts: (1) whether the patient thought that the operation had or had not been worth while, considering the overall result ; $(2)$ the effect of the operation on each symptom ; (3) the post-operative radiological findings and how they correlated with the patient's opinion; and (4) how far the surgical procedure correlated with the radiological findings and the patient's opinion of the result.

\section{Overall Results}

(a) Fifty patients were pleased with the outcome of the operation. Six of these denied having any symptoms at all after the operation, but 42 admitted on direct questioning that they still had mild symptoms of reflux occasionally. The remaining swo patients still had moderately severe symptoms but thought the operation worth while-one because she was able to work in her garden without intolerable discomfort, and the other because she was able to eat a meal without vomiting afterwards. All of these patients were quite emphatic that the operation had been worth while despite transient or mild thoracotomy pain in two patients, some form of persisting dysphagia in 19, and the development of oesophageal stricture at a later date in two. As a result of the surgical procedures additional to the hernial repair there were five instances of post-vagotomy diarrhoea, one of bilious vomiting from an afferent-loop syndrome, and one of dumping.

(b) Ten female and two male patients did not believe the operation to have been worth while. (In addition, one woman died post-operatively from pulmonary embolism.) In eight of these $(12 \%$ of the total) the symptoms of reflux were insufficiently relieved to satisfy the patient on this count. In two patients these symptoms were relieved but were replaced by post-

TABLE IV.-Length of Follow-up in Years of Satisfied and of Dissatisfied

\begin{tabular}{l|c|c|c|c|c|c|c|c|c|c|c}
\hline No. of years: & $<1$ & $1-$ & $2-$ & $3-$ & $4-$ & $5-$ & $6-$ & $7-$ & $8-$ & $9-$ & $10-11$ \\
\hline $\begin{array}{l}\text { Satisfied } \\
\text { Dissatisfied }\end{array}$ & 9 & 15 & 1 & 4 & 7 & 2 & 3 & 4 & 3 & 3 & 1
\end{tabular}


operative symptoms which were just as bad: one of them had severe and apparently permanent post-thoracotomy pain, and the other developed a severe dumping syndrome. It seemed clear in retrospect that in the remaining two patients the hernia was not the major cause of their symptoms. Table IV shows that the incidence of dissatisfied patients was not related to the duration of follow-up.

\section{Effect on Individual Symptoms}

The effect of the operation on some of the commonest preoperative symptoms is shown in Table V. Certain definitions are necessary. (1) "Reflux pain" is epigastric, hypochondrial,

TABLE V.-Effect of Operation on Symptoms

\begin{tabular}{|c|c|c|c|c|c|}
\hline Symptom & & Relieved & $\begin{array}{l}\text { Not } \\
\text { Relieved }\end{array}$ & $\begin{array}{c}\text { Not Present } \\
\text { Pre-op. }\end{array}$ & Not Known \\
\hline 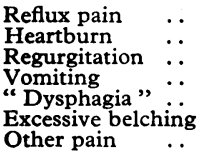 & $\begin{array}{l}\because \\
\because \\
\cdots \\
\cdots \\
\cdots\end{array}$ & $\begin{array}{r}42 \\
43 \\
39 \\
23 \\
21 \\
19 \\
7\end{array}$ & $\begin{array}{l}5 \\
4 \\
12 \\
10 \\
19^{*} \\
15 \\
10\end{array}$ & $\begin{array}{r}6 \\
6 \\
1 \\
14 \\
17 \\
12 \\
29\end{array}$ & $\begin{array}{l}10 \\
10 \\
11 \\
16 \\
12 \\
17 \\
17\end{array}$ \\
\hline
\end{tabular}

* This figure includes 6 patients who did not have dysphagia pre-operatively but did subsequently.

or retrosternal, usually related to posture, and radiating to one or more of the following sites-back, neck, jaw, ears, or arms. (2) "Heartburn" is a retrosternal sensation which radiates to the throat or jaw, tends to be related to food, particularly of certain types, and to posture but not to exertion, and which is not severe enough to be graded by the patient as pain. Severe heartburn was often difficult to distinguish from reflux pain. The severity of these symptoms was graded and the assessment was whether or not they were sufficiently relieved to satisfy the patient. (3) Vomiting is an active rejection which must be differentiated from regurgitation, which is an effortless and uncontrollable efflux from the oesophagus. (4) "Dysphagia" refers to a sensation of a "lump," or fullness in the chest related to food, or that food or fluid is " held up," whether or not it is possible to continue eating or drinking. It includes dysphagia produced by the operation, and bolus obstruction, which was a rare event. Dysphagia was assessed as present or not present. (5) "Other pain" refers to chest or abdominal pain other than "reflux pain."

The results show that there is a 9 to $1(90 \%)$ chance of reflux pain and heartburn being usefully reduced in severity by the operation, and a 3.25 to $1(77 \%)$ chance of regurgitation being relieved. Vomiting was a common and important symptom in at least half of the patients pre-operatively, and was relieved in $70 \%$ of those who had had it. A feeling of "dysphagia" was present pre-operatively in 34 patients, 21 of whom had no dysphagia more than three months after the operation. Six patients who did not have dysphagia before the operation had a persistent form of dsyphagia afterwards. Excessive belching was present in at least half and was relieved in half of those who had it ; "other pain" was present in at least one-quarter and relieved in about one-half of these.

\section{Radiological Findings and Comparison of Clinical and Radiological Result}

Of 45 patients with adequate radiological follow-up, 17 had neither hernia nor reflux, 13 had reflux but no hernia, and 15 had a hernia and reflux. In the Diagram the patients' assessment of the overall result is compared with the radiological findings. The most striking feature is that 36 of the 45 patients with adequate radiological follow-up thought that the operation had been worth while, yet only 13 of the 36 had no radiological evidence of hernia or reflux, 11 of them had a hernia and reflux, and 12 had reflux without a hernia.
Table VI shows the relation between the severity of the postoperative symptoms of reflux and the $x$-ray assessment of reflux in the patients personally examined. The symptoms of reflux pain, heartburn, and regurgitation were each scored on a 0 to 3 scale and the sum of these scores rated as: $0 ; 1$ to $3=$ slight symptoms; 3 to $6=$ moderate; and more than $6=$ severe symptoms. The degree of reflux seen at fluoroscopy was assessed as 0 , slight, moderate, and severe. In Table VI the patients have been separated into those who had had a simple
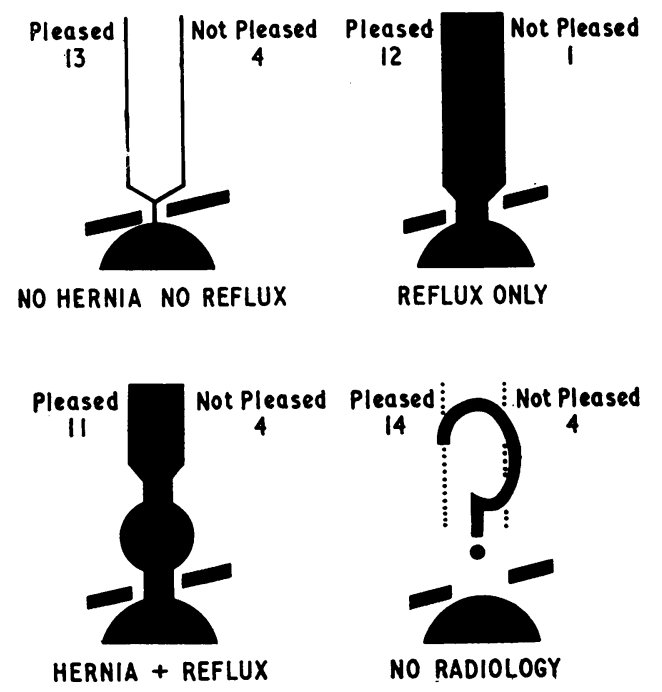

Patients' assessment of result compared with radiological appearances. "Pleased"=operation was worth while ; "Not pleased"=not worth while. The cardiac sphincter is represented by a constriction between the body of the oesophagus and the stomach or herniated loculus, and the diaphragm by a thick sloping line-interrupted at the oesophageal hiatus.

TABLE VI.-Relation Between Severity of Symptoms and Radiological TABLE VI.-Relation Between Severity of Symptoms
Evidence of Reflux After Repair

\begin{tabular}{|c|c|c|c|c|c|c|c|c|}
\hline \multirow{3}{*}{$\begin{array}{l}\text { Severity o } \\
\text { Symptom } \\
\text { of Reflux }\end{array}$} & \multicolumn{8}{|c|}{$X$-ray Assessment of Reflux } \\
\hline & \multicolumn{4}{|c|}{ Simple Repair } & \multicolumn{4}{|c|}{ Repair + Vagotomy } \\
\hline & None & Slight & Mod. & Severe & None & Slight & Mod. & Severe \\
\hline $\begin{array}{l}\text { None } \\
\text { Slight } \\
\text { Moderate } \\
\text { Severe }\end{array}$ & $\begin{array}{l}1 \\
3 \\
1 \\
0\end{array}$ & $\begin{array}{l}1 \\
2 \\
3 \\
0\end{array}$ & $\begin{array}{l}0 \\
5 \\
0 \\
1\end{array}$ & $\begin{array}{l}0 \\
1 \\
0 \\
0\end{array}$ & $\begin{array}{l}0 \\
8 \\
0 \\
0\end{array}$ & $\begin{array}{l}2 \\
1 \\
1 \\
0\end{array}$ & $\begin{array}{l}0 \\
1 \\
1 \\
0\end{array}$ & $\begin{array}{l}0 \\
2 \\
1 \\
0\end{array}$ \\
\hline
\end{tabular}

These figures refer to 35 of the 37 patients personally examined; the other 2 patients who had a partial gastrectomy are excluded.

repair and those who had had a vagotomy and drainage, because of the possibility that the latter procedure might have influenced the severity of the symptoms. There is some discrepancy between the clinical and radiological evidence of reflux; for example, we found slight reflux in three out of four patients who denied having any symptoms at all since the operation, and we failed to demonstrate reflux in 12 patients who claimed slight or moderate symptoms. Severe reflux was seen in four patients who claimed to have only slight or moderate symptoms.

These discrepancies are of two kinds, however: gross, where the presence or absence of a hernia does not correlate with symptoms ; and slight, where the severity of symptoms correlates fairly well but not precisely with the radiological estimate of the amount of reflux.

\section{Correlation of Surgical Procedure With Patient's Opinion and Radiological Result}

This is shown in Table VII. About the same proportion of patients were satisfied after the transthoracic approach as were satisfied after the transabdominal. Similarly, the proportion of patients satisfied is not obviously altered by a vagotomy and 
drainage. The figures in Table VI, although also small, suggest the same conclusion-that vagotomy and drainage does not influence the severity of symptoms of reflux.

The total amount of reflux found is about the same after the transabdominal or transthoracic approach, but there were more hernias present after the transabdominal approach. The operative procedure did not otherwise appear to correlate with the radiological result.

\begin{tabular}{|c|c|c|c|c|c|c|}
\hline \multirow[b]{2}{*}{$\begin{array}{c}\text { Type of } \\
\text { Operation }\end{array}$} & & \multicolumn{2}{|c|}{ Patient's Opinion ${ }^{*}$} & \multicolumn{3}{|c|}{$X$-ray Findings $\dagger$} \\
\hline & & $\begin{array}{l}\text { Worth } \\
\text { While }\end{array}$ & $\begin{array}{l}\text { Not } \\
\text { Worth } \\
\text { While }\end{array}$ & $\begin{array}{l}\text { No Hernia } \\
\text { No Reflux }\end{array}$ & $\begin{array}{l}\text { Hernia } \\
\text { + Reflux }\end{array}$ & $\underset{\text { Only }}{\text { Reflux }}$ \\
\hline $\begin{array}{l}\text { Transthoracic } \\
\text { Transabdominal } \\
\text { Simple repair } \\
\text { Vagotomy } \\
\text { Gastrectomy }\end{array}$ & $\begin{array}{l}\cdots \\
\cdots \\
\cdots\end{array}$ & $\begin{array}{r}25 \\
25 \\
3 \\
19 \\
3\end{array}$ & $\begin{array}{l}7 \\
6 \\
1 \\
4 \\
1\end{array}$ & $\begin{array}{r}6 \\
11 \\
0 \\
8 \\
3\end{array}$ & $\begin{array}{r}5 \\
10 \\
1 \\
8 \\
1\end{array}$ & $\begin{array}{l}9 \\
4 \\
1 \\
3 \\
0\end{array}$ \\
\hline
\end{tabular}

* These figures refer to the total series of 63 patients.

+ These figures refer to the 45 patients on whom there was adequate radiological follow-up.

\section{Discussion}

Despite the reputation of hiatus hernia as the abdominal mimic there is a well-defined group of symptoms which can rightly be attributed to gastro-oesophageal reflux resulting from the presence of the hernia. This study emphasizes that these symptoms of reflux pain, heartburn with a postural relationship, and regurgitation are the important diagnostic features, and are those which are most likely to be relieved by surgical repair regardless of the presence of any other lesion. In addition, vomiting and a feeling of distension in the chest and abdomen associated with food, and a feeling of a "lump," are symptoms commonly associated with hiatus hernia and are often relieved by the repair. These latter symptoms are much less specific, however, and to advise surgery for repair of hiatus hernia without the symptoms of gastro-oesophageal reflux or regurgitation is likely to be unrewarding and to delay attention to the primary cause of the patients' symptoms.

The amount of relief of these symptoms did not seem to be greatly influenced by the operative approach nor by vagotomy or partial gastrectomy. Nor is reduction of the hernia by itself the most important part of the operation, because (a) this did not necessarily prevent reflux, and $(b)$ many of the patients who still had hernias thought the operation had been worth while. It seems likely that the major cause of relief is a critical reduction in the quantity of gastric juice which reaches the oesophagus and pharynx and the ease with which it does so.

Since we do not know precisely what normally prevents reflux it is not possible to devise an appropriate operative technique, and therefore it is not remarkable that radiological evidence of reflux was found in well over half of those operated upon. When the oesophagogastric junction is displaced upwards into the chest the only remaining defence against reflux from the hernia into the oesophagus is the intrinsic sphincter. Some years ago when it first became possible to study this physiological sphincter by manometry we thought that it was the tone of this sphincter which determined whether reflux occurred or not (Atkinson, Edwards, Honour, and Rowlands, 1957). Later it became apparent that this explanation was untenable and that the role of the sphincter was a minor one, since it could not withstand the difference between intra-abdominal and intrathoracic pressure (Edwards, 1961, 1962). In the presence of a hiatus hernia the amount and freedom of flow of gastric contents into the oesophagus depends on the difference between the pressure in the intrathoracic loculus and that in the oesophagus. If this difference is less than the closing pressure of the sphincter no reflux will occur, but if the difference is large, then reflux will be violent and the cricopharyngeal sphincter will also be breached. The oesophageal hiatus of the diaphragm controls to some extent the rate of transfer of pressure from the intra-abdominal to the intrathoracic stomach, and is probably an essential component of the flutter-valve anti-reflux mechanism (Edwards, 1961, 1962). Hence an operation which reduces the size of the opening in the diaphragm is likely to alleviate the patient's symptoms even if the hernia is not completely reduced and some reflux can still be demonstrated radiologically.

Whether this theory is correct or not the value to the patient of surgical repair of hiatus hernia cannot be judged from the radiological result. There can be no doubt at all that most of the patients in this series were very pleased that they had had the operation because medical measures had failed to provide sufficient relief. Each patient was told specifically that we were trying to find out whether surgery was a useful treatment for hiatus hernia and therefore that her replies to our questionary must not be influenced in any way by any sense of gratitude or loyalty to the physicians who advised her to have the operation or to the surgeon who performed it. We were all the more impressed by the results because it was clear that only those with intractable symptoms had been referred for surgery from a large gastro-enterological clinic. There is no doubt that this is the correct policy, because the majority of these patients respond satisfactorily to medical treatment, and long-term studies have shown that more than $50 \%$ are improved 10 years later (Rex, Andersen, Bartholomew, and Cain, 1961).

As a result of this survey, however, we wonder whether we, and possibly other physicians, are too reluctant to advise surgery, and continue to persevere with medical measures even when these are clearly not providing sufficient relief to some of our patients. It is more difficult for these patients to "earn" an operation than patients with dyspepsia from peptic ulcer or cholecystitis, although the symptoms of reflux oesophagitis can be at least as distressing and resistant to medical treatment in the more severe cases. One reason for the reluctance to advise surgery is that the surgical repair of hiatus hernia is generally considered to be more hazardous and less successful in relieving symptoms than operative procedures for ulcer and gall-bladder dyspepsia. Yet in this series the main sources of post-operative morbidity were $(a)$ the presence of other lesions in addition to the hiatus hernia, and $(b)$ the performance of other operative procedures in addition to the repair. Another possible reason for reluctance to operate is that whereas partial gastrectomy or cholecystectomy is a supposedly rational procedure, the various operative techniques used in repairing a hiatus hernia are based on hypotheses, of which there are so many that several must be incorrect. It is our impression, however, that following a simple hernial repair the chances of the symptoms of reflux being relieved are high even when only the most severe cases are operated on, and the chances of replacing the reflux symptoms by other unpleasant symptoms are very low. "Hiatus hernia" is very much a disease of symptoms, the severity of which the observer cannot easily assess, and which often do not appear to correlate closely with the radiological signs of an intrathoracic loculus of stomach and the reflux of barium.

\section{Summary}

During an 11-year period 63 patients were operated upon for repair of a hiatus hernia by one surgeon. Three physicians who had not seen the patients before tried to assess (1) the patients' opinions about whether the operation had been worth while, (2) which symptoms had been most frequently reduced in severity, (3) how often radiological evidence of hiatus hernia and/or reflux persisted, and (4) whether attempts to reduce acid secretion influenced the result.

Fifty patients felt that the operation had been worth while. Dissatisfaction resulted from various causes, but in eight it was because of insufficient relief of symptoms of reflux. Reflux pain 
and heartburn were usefully reduced in $90 \%$, regurgitation in $77 \%$, and vomiting in $70 \%$ of those who had had it. Of 45 patients with adequate radiological follow-up, 15 had radiological evidence of hernia and reflux, 13 of reflux without hernia, and 17 had no radiological evidence of hernia or reflux. The value of the operation to the patient could not be judged from the radiological result.

Attempts to reduce acid secretion did not seem to improve the results, and they added to the morbidity.

Physicians are probably unduly reluctant to recommend surgery in the treatment of hiatus hernia.

We are particularly grateful to Drs. F. Avery Jones and T. D. Kellock and to Mr. J. W. P. Gummer. All the patients included in this survey were in their care; the opinions expressed in this report are entirely ours. We should like also to thank Dr. F. Pygott for information about the number of diagnostic radiological examinations at Central Middlesex Hospital and Miss B. White for assistance with the records. One of us (S. F. P.) was in receipt of a grant from the Royal Australasian College of Physicians as a travelling scholar.

\section{REFERENCES}

Atkinson, M., Edwards, D. A. W., Honour, A. J., and Rowlands, E. N. (1957). Lancet, 2, 918.

Edwards, D. A. W. (1961). Brit. F. Radiol., 34, 474.

(1962). In Surgical Physiology of the Gastro-intestinal Tract, edited by Adam W. Smith, p. 24. Roy. Coll. Surg. Edinburgh. Rex, J. C., Andersen, H. A., Bartholomew, L. G., and Cain, J. C. (1961) 7. Amer. med. Ass., 178, 271.

Wells, C., and Johnston, J. H. (1955). Lancet, 1, 937.

\title{
Ability of Men to Return to Work After Cardiac Infarction
}

\author{
D. E. SHARLAND, ${ }^{*}$ B.SC., M.B., M.R.C.P.
}

Brit. med. F., 1964, 2, 718-720

While the medical problems concerned with the development of ischaemic heart disease have fired the imagination of innumerable workers, the study of the social consequences has been largely neglected. Much of the literature which does consider this facet of the problem comes from the United States of America, and it usually consists of highly selected series-that is, patients seen in private practice or in work classification units-and, moreover, it emanates from a country where a very different social system exists.

Master and Dack (1940), from the U.S.A., report a follow-up of 415 patients of both sexes ranging in age from 30 to 89 who had suffered one, two, or three infarctions. There was an overall rate of return to work of $53 \%$, but if only those under 60 years of age were considered the rate of return was $57 \%$. For all ages the overall rate of return to work after a first infarction was $59 \%$. Those in the higher social categories were more successful than others, so that $84 \%$ of physicians returned to work, in contrast to only 50 to $55 \%$ of those classed as general workers and labourers. Cole, Singian, and Katz (1954) reported a series of 285 patients aged 30-89 who survived for over two months after a first cardiac infarction. Of this group, which included cases complicated by hypertension and diabetes, about two-thirds were able to resume moderate or complete activity ; whether this meant usual work is not entirely clear. In a group of 184 employees of the Eastman Kodak Co. aged 25-64, 82\% were able to resume work, though 20 had to retire prematurely because of total and permanent disability (Crain and Morris, 1956). Papp and Shirley Smith (1951) reported a series of 200 consecutive cases seen in private and hospital practice in this country and showed that in patients whose ages ranged from 30 to $79,65 \%$ of those who suffered cardiac infarction of slight or moderate severity resumed normal activity, while only $33 \%$ of those suffering a severe cardiac infarction were able to resume normal activity, usually in a sedentary occupation. The large difference between these groups was due to the difference in mortality in the first six months after the initial infarction$1.4 \%$ in those sustaining a mild infarction, $5.1 \%$ in those sustaining a moderately severe infarction, and $36 \%$ in those suffering a severe infarction.

The increasing interest in the employability of patients with heart disease in the United States is reflected in the setting up

* Research Registrar, Central Middlesex Hospital, London, in receipt of grant from M.R.C. of cardiac work classification units, the first being started at the Bellevue Hospital in 1941 (Bronstein, 1959).

\section{Present Study}

The present data were obtained during the course of a study of the effects of a low-fat diet compared with an ordinary diet on the progress of ischaemic heart disease. A consecutive series of men were selected for the trial. They were all under the age of 65 , had sustained one episode of cardiac infarction, and were subsequently free from serious complications such as persistent heart failure. Cases where the cardiac infarction was thought to be a complication of an existing disease-for example, diabetes or severe hypertension-were likewise excluded. Many of the men received up to three months' anticoagulant treatment, but none were on long-term anticoagulants. While the details of this dietary study will form the subject of another communication, it may be indicated that there is no evidence of any significant difference in the progress of the men on the two different dietary regimens; for this study they have been grouped together. Men aged 60-64 were excluded as often these had retired or were on the point of retirement. The 212 cases described were collected in approximately four years from three large district general hospitals.

After discharge from hospital every effort was made to get a patient back to work. At the time of entry to the dietary trial information concerning the nature of the job held prior to the cardiac infarction was obtained and, in most cases, the date of return to work, whether it was part-time or full-time

TABLE I.-Status, With Respect to Work, of a Group of Men Under 60 Years of Age Who Survived One Cardiac Infarction and Who Were Followed for One to Three Years up to 31 March 1962

\begin{tabular}{|c|c|c|c|c|c|c|c|c|c|}
\hline \multirow{2}{*}{$\begin{array}{c}\text { Time } \\
\text { after } \\
\text { Initial } \\
\text { Infarct }\end{array}$} & \multirow{2}{*}{$\begin{array}{l}\text { No. of } \\
\text { Patients }\end{array}$} & \multicolumn{2}{|c|}{$\begin{array}{l}\text { No. at Full- } \\
\text { time Work }\end{array}$} & \multirow{2}{*}{$\begin{array}{c}\text { No. at } \\
\text { Part- } \\
\text { time } \\
\text { Work }\end{array}$} & \multirow{2}{*}{$\begin{array}{c}\text { Men at } \\
\text { Work } \\
\text { (F/T } \\
\text { or P/T) }\end{array}$} & \multirow{2}{*}{$\begin{array}{c}\text { No. } \\
\text { not } \\
\text { at } \\
\text { Work }\end{array}$} & \multicolumn{2}{|c|}{ Dead } & \multirow{2}{*}{$\begin{array}{c}\text { No. } \\
\text { Alive } \\
\text { but } \\
\text { Work } \\
\text { Status } \\
\text { Un- } \\
\text { known }\end{array}$} \\
\hline & & $\underset{\text { Job }}{\text { Usual }}$ & $\begin{array}{l}\text { Dif- } \\
\text { ferent } \\
\text { Job }\end{array}$ & & & & No. & $\%$ & \\
\hline $\begin{array}{l}3 \text { months } \\
4, " \\
6, " \\
1 \text { year } \\
2 \text { years } \\
3 \text { ", }\end{array}$ & $\begin{array}{r}212 \\
212 \\
212 \\
212 \\
171 \\
96\end{array}$ & $\begin{array}{r}58 \\
96 \\
120 \\
138 \\
107 \\
58\end{array}$ & $\begin{array}{l}15 \\
23 \\
33 \\
40 \\
35 \\
16\end{array}$ & $\begin{array}{r}43 \\
35 \\
20 \\
4 \\
5 \\
2\end{array}$ & $\begin{array}{l}55 \% \\
73 \% \\
82 \% \\
86 \% \\
86 \% \\
79 \%\end{array}$ & $\begin{array}{r}89 \\
51 \\
28 \\
15 \\
3 \\
4\end{array}$ & $\begin{array}{r}5 \\
5 \\
7 \\
9 \\
16 \\
13\end{array}$ & $\begin{array}{r}2 \cdot 3 \\
2 \cdot 3 \\
3 \cdot 3 \\
4 \cdot 2 \\
9 \cdot 4 \\
14 \cdot 0\end{array}$ & $\begin{array}{l}2 \\
2 \\
4 \\
6 \\
5 \\
3\end{array}$ \\
\hline
\end{tabular}

